\title{
The Anti-Inflammatory Properties of the Topical Application of Human Milk in Dermal and Optical Diseases
}

\author{
Leila Amiri-Farahani $\mathbb{D}^{1}{ }^{1}$ Zahra Sharifi-Heris, ${ }^{2}$ and Faraz Mojab ${ }^{3}$ \\ ${ }^{1}$ Department of Reproductive Health and Midwifery, Nursing Care Research Center, School of Nursing and Midwifery, \\ Iran University of Medical Sciences, Tehran, Iran \\ ${ }^{2}$ Sue \& Bill Gross School of Nursing, University of California at Irvine, Irvine, CA, USA \\ ${ }^{3}$ Department of Pharmacognosy, School of Pharmacy, Shahid Beheshti University of Medical Sciences, Tehran, Iran
}

Correspondence should be addressed to Leila Amiri-Farahani; amirifarahani.l@iums.ac.ir

Received 7 February 2020; Revised 12 June 2020; Accepted 27 June 2020; Published 24 July 2020

Academic Editor: Jairo Kenupp Bastos

Copyright (c) 2020 Leila Amiri-Farahani et al. This is an open access article distributed under the Creative Commons Attribution License, which permits unrestricted use, distribution, and reproduction in any medium, provided the original work is properly cited.

\begin{abstract}
Background and Objective. The topical human milk (THM) is one of the traditional remedies for various cases of injuries, ulcers, and infections for decades. No study was found reporting the adverse effects of human milk. The current study reviews the antiinflammatory properties of human milk when topically applied to dermal and optical diseases. Methods. The various datasets including Ovid, PubMed, Google Scholar, Science Direct, Magiran, Irandoc, SID, and IranMedex were searched from 1990 to 2018. From the 119 reviewed articles, 20 articles were selected to be included in the current article. Results. There is a consensus among the literature and ancient texts regarding the effectiveness of THM in curing the various types of skin damages, such as cord separation, atopic dermatitis, diaper dermatitis, conjunctivitis, scratches, insect bite, perineal ulcer, and nipple ulcer. However, the importance of its application has not been given much attention. Conclusion. According to the information obtained from the articles reviewed, the THM appears to be an effective, safe, and available treatment compared to conventional chemical treatments. This study suggests THM as an alternative remedy to minimize the frequent use of chemical-based treatments. More research may be beneficial to reach certainty in terms of curative properties of THM in similar or different injuries in different populations.
\end{abstract}

\section{Background}

The human milk (HM) consumption, orally or topically, has beneficial effects on both mother and child's health. According to the literature, it was shown that feeding with HM leads to increased resistance to asthma, diarrhea, respiratory infections, urinary tract infections, otitis media, intestinal infections, celiac disease, breast cancer, leukemia, neonatal diabetes, eczema, allergic diseases, influenza, cardiovascular disease, and mental disorders and reduced risk of obesity in childhood and adulthood [1]. The advantages of breastfeeding for mothers include postpartum weight loss, lower risk for breast, ovarian, and endometrial cancers, bone strength, and lower risk of joint rheumatoid arthritis [1, 2].
Today, the topical application of human milk (THM) has been documented to treat the optical inflammations including conjunctivitis in ancient Egypt, Greek, India, and Rome for decades [3]. The THM also has been used as a traditional practice in healing the infants' umbilical cords and accelerating the cord separation in the communities in KwazuluNatal, as well as in some parts of Kenya, Turkey, India, and China [4]. Furthermore, eczema and diaper dermatitis as common skin inflammations among infants have been cured using THM [5]. The results of a qualitative study in Zambia show the positive experiences following the THM application to prevent and treat the umbilical cord inflammations [6]. The promising effects of THM also have been indicated among women in improving the nipple sore and perineal ulcer $[7,8]$. 
HM consists of anti-inflammatory and antioxidant components, including vitamins $\mathrm{A}, \mathrm{C}$, and $\mathrm{E}$, catalase enzymes, glutathione peroxidases, prostaglandins, and platelet activators as well as leukocytes that regulate the immune system $[9,10]$. The aforementioned components may be the potential underlying cause for the curative properties of the THM.

Today, the tendency toward traditional treatments is increasing across the world especially developed countries [11]. A variety of studies have shown the negative consequences of conventional medicine in various populations including children. According to an investigation, people reported expensiveness, side effects, the difference in physicians' opinions, and distrust in physicians as potential disadvantages of conventional medications [12]. The THM seems to be a safe, accessible, trustable, and noninvasive alternative for domestic application, especially in mothers and infants, as it is produced in the human body and contains natural anti-inflammatory components [13].

Despite the effectiveness of THM in different cultures and ethnicities in underdeveloped and developing countries, its use has been less widely considered among health professionals and staff especially in developed countries [5]. The current study aimed to review the literature to assess the effect of THM on various inflammations.

\section{Methods}

2.1. Design. The current literature review study was completed following the academic standards for conducting integrative literature reviews [14]. As an additional element of quality assurance, we applied the Preferred Reporting Items for Systematic Reviews and Meta-Analyses (PRISMA) to structure the study [15]. The studies were included if they were interventional or review papers.

2.2. Setting. Journal articles were examined in PubMed, CINAHL, PsycINFO, Web of Science, Ovid, Google Scholar, Science Direct, Cochrane Library, Magiran, Irandoc, and SID, using keywords that probe the significance of HM applied topically as a form of treatment for ulcers and inflammatory lesions: "human milk," "colostrum," "topical application," "wound," "wound healing," "ulcer," and "sore." These articles were peer-reviewed and published from 1990 to 2018.

2.3. Sample. Relevant articles were included through a three-step search strategy. Initially, 119 articles were obtained using the aforementioned keywords. These results were then screened using exclusionary criteria. A total of 27 articles were excluded as they were duplicated. For the rest of the articles, the exclusion criteria included (1) nonhuman samples and (2) protocol-based articles with no reported results. A total of 72 articles were excluded, leaving 20 articles for review (Figure 1).

2.4. Measurement. The author (ZSH) appraised each of the 20 articles which were peer-reviewed by another author (LAF) for accuracy. The extracted data included the title, country and city, participants characteristics, intervention description, control or/and comparison groups, length of follow-up, the measure of outcome variables, and main results (Table 1) (among the included studies, the results of which were reported in terms of hours, the results were rounded).

\section{Results and Discussion}

The HM has distinct anti-inflammatory components and properties that may explain the effectiveness of the HM when topically applied. These compounds include the following:

Lipids. The triacylglycerides, diacylglycerides, monoacylglycerides, free fatty acids, sphingomyelins, phospholipids, and cholesterol are the main lipids found in HM [32-34]. The HM lipids have been shown to provide a protective barrier against several types of invasive pathogens including Group B Streptococcus (GBS) on the mucosal surface [35].

Proteins. HM consists of over 400 various proteins including caseins, whey, and mucin which executes the inhibitory functions in response to pathogenic microbes [36]. Leucocytes as known anti-inflammatory components of the body floods account for $80 \%-90 \%$ of the HM proteins [9].

Carbohydrates. HM contains a vast range of complex carbohydrates. The most prevalent is lactose. Lactose is a disaccharide and consists of glucose which covalently bounds to galactose. Their function instead is to nourish the gastrointestinal microbiota [37].

Antibodies. The Secretory Immunoglobulin A ( $\operatorname{IgA})$ in $\mathrm{HM}$ provides an immunological defense to protect the infant with the unmatured immune system against the pathogenic microorganisms [38]. There are also numerous antibody classes in HM which provide defense against neonatal GBS infection [39].

\section{Topical Applications of HM (THM)}

Almost all of the reviewed studies were focused on mothers and infants. The studies generally had consensus on the significant positive impacts of THM in women and their infants.

4.1. Effect of THM on Infants. The HM has been used in the bacterial colonization, umbilical cord separation time (UCST) [4], chlamydia conjunctivitis, rhinitis, ocular dryness, ocular lesions, diaper rash, eczema, and nipple sore [8] as well as bites, infectious wounds, burns, and rubbing [20].

4.1.1. Umbilical Cord. An umbilical cord infection is the major cause of sepsis in newborns that may lead to death in some cases [16]. One of the major underlying causes of umbilical cord infections is a long separation time [40]. The WHO recommended keeping the cord dry as much as possible, and it also suggested a topical antiseptics such as 


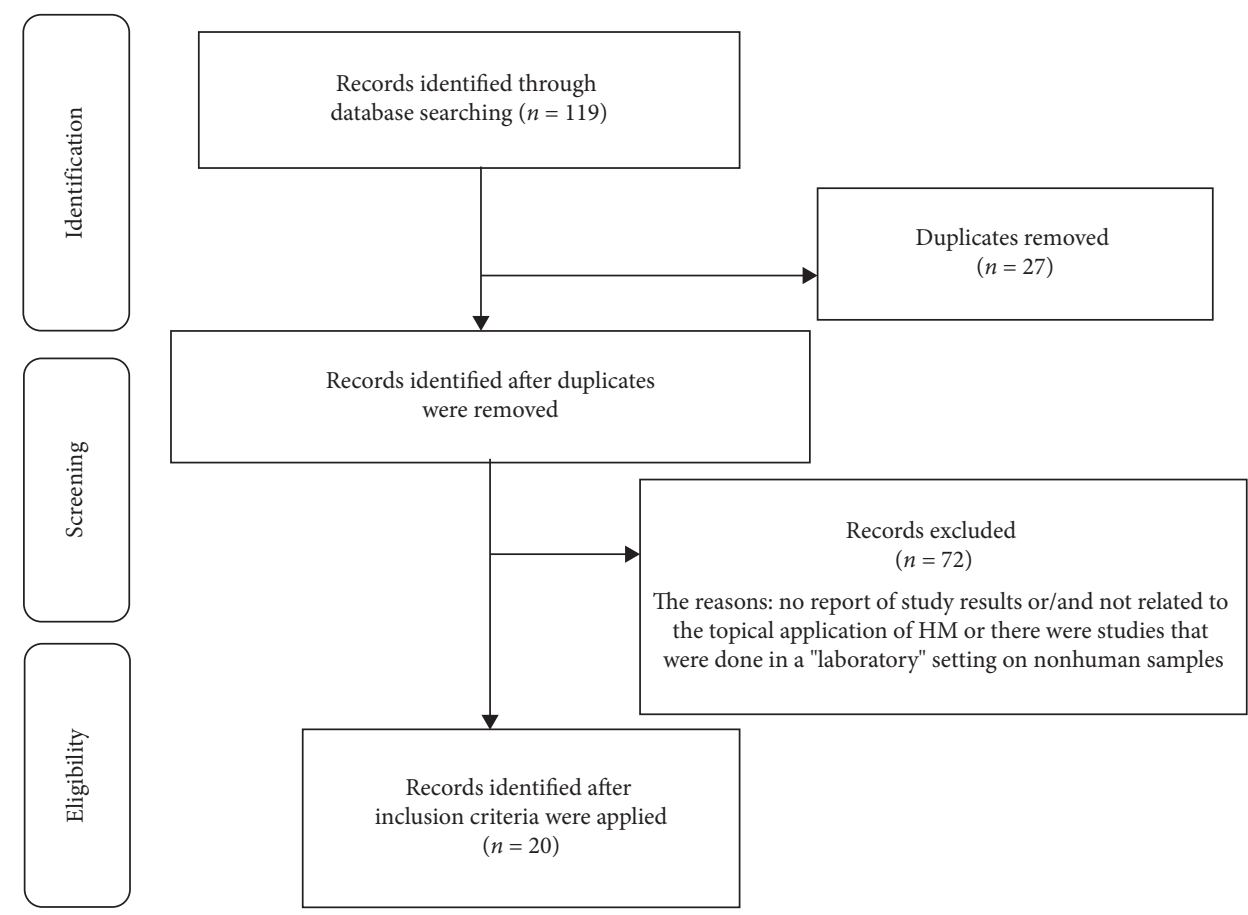

Figure 1: The articles included in the study.

chlorhexidine in poor health conditions and high levels of infections [41]. The THM is one of the effective traditional treatments commonly applied for shortening UCST or preventing and treating the umbilical cord inflammation in middle eastern.

In 2008, Taffazoli conducted a study to investigate the effect of THM on the bacterial colonization of the umbilical cord region. The findings revealed that first, Staphylococcus epidermidis, Staphylococcus aureus, Escherichia coli, and Klebsiella pneumonia were the most commonly grown organisms in the umbilical region; second, bacterial colonization was significantly lower in THM group compared with the control group $(P<0.001)[42]$.

In this regard, Ibhanesebhor and Otobo showed that the susceptibility level of Escherichia coli to colostrum and THM was $57 \%$ and $28 \%$, respectively. The Staphylococcus aureus was reported to be sensitive about $50 \%$ and $0 \%$ to colostrum and THM, respectively [43]. In this regard, Ramsey et al. conducted an experimental study on 229 host cells infected with Chlamydia trachomatis in a laboratory environment. The milk (colostrum and noncolostrum milk) samples were obtained from 13 lactating postpartum women and the samples were added to the infected cells. They observed that 11,2 , and 1 of the samples showed $85 \%, 75 \%$, and $44 \%$ chlamydia growth inhibition started within less than 15 minutes. It was also noticed that colostrum is more effective than mature milk. In addition, they suggested that the used dose plays the main role in the effectiveness of THM [44].

Literature also concerned with the umbilical cord separation time using THM in comparison with the dry-care control group (DCC). Allam et al. studied the effect of THM on UCST and bacterial colonization recruiting 400 neonates that are equally allocated into THM and DCC groups. The results indicated that the umbilical cord of $80 \%$ of the neonates in the THM group was separated from the 3rd to 4 th days, and the rest of the group (20\%) lost their umbilical cords on the 5 th to 6 th days. The UCST was significantly lower in the THM group ( $4 \pm 20$ days) than that the DCC group $(7 \pm 10$ days $)(P<0.001)$. Also, Escherichia coli and Staphylococcus aureus were 2\% less in the THM group compared with the DCC group [17]. To answer the same research question, Aghamohammadi et al. recruited 130 newborns randomly allocated into two equal THM and DCC groups. According to the results, UCST was significantly longer in the DCC group $(8 \pm 2$ days) than that in the HM group $(6 \pm 1$ days $)(P<0.001)$ [18]. Additionally, Pujar et al. also supported the results of the previous studies enrolling 60 newborns. The findings of this study showed that UCST was significantly shorter in the THM group (5 days) when compared to that in the control group ( 9 days) $(P<0.05)$ [19]. Furthermore, Dhanawade and Amiri-Farahani et al. confirmed the previous findings showing a significantly lower UCST in THM ((5-6) \pm 3 days) compared with DCC group $((7-9) \pm 3$ days $)(P<0.001)[20,21]$.

Studies also compared the THM efficiency with commonly applied conventional medications including ethanol, povidone-iodine, ethyl alcohol, silver sulfadiazine, and chlorhexidine. On this point, Golshan and Hossein conducted a randomized clinical trial (RCT) to compare the effects of THM, DCC, and ethanol on UCST and omphalitis on a total of 300 neonates. The UCST was significantly shorter in the THM than those in the DCC $(P=0.0001)$ and ethanol groups $(P=0.003)$. No significant difference was reported in the frequency of omphalitis in the three groups [22]. The findings from another RCT performed by Mahrous et al. on 100 newborns confirmed the results of the previous 
TABLE 1: Randomized trials evaluating the impact of topical application of HM on maternal and child health outcomes.

\begin{tabular}{|c|c|c|c|c|}
\hline $\begin{array}{l}\text { Author, year, and } \\
\text { location }\end{array}$ & Study groups & Intervention & $\begin{array}{l}\text { Variable measured/ } \\
\text { scale }\end{array}$ & Results \\
\hline
\end{tabular}

Effect of THM on infants

Umbilical cord

Lyngdoh et al., 2018, India [16]

HM $(n=35)$; chlorhexidine $(n=35)$; DCC $(n=35)$

Allam et al., 2015, Egypt [17]

Aghamohammadi et al., 2012, Iran [18]

HM $(n=65)$; DCC $(n=65)$

Pujar et al., 2013, India [19]

Dhanawade, 2014, India [20]

HM $(n=45)$; DCC $(n=45)$

Amiri-farahani et al., 2007, Iran [21]

Golshan and Hossein, 2013, Iran [22]

HM $(n=100)$; DCC $(n=100) ; 70 \%$ ethanol $(n=100)$

Mahrous et al., 2012, Egypt [23]
HM and chlorhexidine: topical application of $\mathrm{HM}$ or $4 \%$ chlorhexidine was done by sterile swab once a day till the cords fall off; DCC: NI.

HM: mothers used about 4-6 foremilk (before lactation) cord stump and let the milk to completely dry. The starting time for applying the pertinent substances is considered 4 hours after birth. The researchers asked the mother to apply milk drops 3 times a day since the 4 th hours of birth until UCS and 2 days after; DCC: NI.

HM: mother's secreted milk was directly applied to the remaining part of the cord and allowed the milk to get completely dry. This intervention beginning time was 3 hours after birth and then every 8 hours for 2 days after UCST; DCC: NI.

HM: fresh mother milk was applied using a sterile swab twice in a day for 3 days; DCC: NI.

HM: approximately $1 \mathrm{ml}$ of fresh mother milk is applied by using sterile buds on the cord stump and let them 10 minutes dry; DCC: NI.

HM: mothers applied their foremilk to their infants' umbilical stump by $3 \mathrm{~h}$ after birth and continued every $12 \mathrm{~h}$ until 2 days after UCS; DCC: NI.

HM: mothers in groups HM and ethanol washed the area of the umbilical cord with their milk and ethanol 70\%, respectively, with the frequency of twice a day for two days after UCS; DCC: NI. $\mathrm{HM}$ or $70 \%$ ethanol: mothers of each group applied pertinent substances topically every 8 hours to the area until two days after USC and allow them to dry without washing
HM: $9 \pm 2$; chlorhexidine: $13 \pm 3$; DCC: $11 \pm 3$ days $(P=0.001)$

UCST HM: $4 \pm 20$; DCC: $7 \pm 10$ days $(P<0.001)$

UCST

HM: $6 \pm 1$; DCC: $8 \pm 2$ days $(P<0.001)$

UCST

HM: 5; DCC: 9 days $(P<0.05)$

UCST

HM: 5; DCC: 9 days $(P<0.05)$

UCST

HM: $6 \pm 2$; DCC: $7 \pm 3$ days $(P<0.016)$

HM: $7 \pm 2$; DCC: $8 \pm 2$; ethanol: $9 \pm 2$ days; the results showed significant difference of UCST between HM and ethanol $(P<0.0001)$ and DCC groups $(P<0.003)$

UCST

HM: $4 \pm 1 ; 70 \%$ ethanol: $8 \pm 2$ days $(P<0.001)$ them out. 
TABle 1: Continued.

\begin{tabular}{|c|c|c|c|c|}
\hline $\begin{array}{l}\text { Author, year, and } \\
\text { location }\end{array}$ & Study groups & Intervention & $\begin{array}{l}\text { Variable measured/ } \\
\text { scale }\end{array}$ & Results \\
\hline $\begin{array}{l}\text { Vural and Kisa, 2006, } \\
\text { Turkey [4] }\end{array}$ & $\begin{array}{l}\text { HM }(n=50) ; \text { DCC } \\
(n=50) ; \text { povidone- } \\
\quad \text { iodine }(n=50)\end{array}$ & $\begin{array}{l}\text { HM: fresh mother milk was } \\
\text { directly applied to the distal } \\
\text { end edge of the stump twice a } \\
\text { day for } 2 \text { days after the cord fell } \\
\text { off; DCC: NI; povidone-iodine } \\
\text { group: they used povidone- } \\
\text { iodine to completely cover the } \\
\text { cut edge of the stump twice a } \\
\text { day umbilicus for } 2 \text { days after } \\
\text { UCS. }\end{array}$ & UCST & $\begin{array}{l}\text { HM: } 7 \pm 2 \text {; DCC: } 8 \pm 3 \text {; } \\
\text { povidone-iodine: } 10 \pm 3 \text { days } \\
\quad(P<0.05)\end{array}$ \\
\hline $\begin{array}{l}\text { Ahmadpour-Kacho } \\
\text { et al., 2006, Iran [24] }\end{array}$ & $\begin{array}{l}\text { HM }(n=79) ; \text { DCC } \\
\quad(n=78) ; \text { silver } \\
\text { sulfadiazine }(n=77) ; \\
\text { ethyl alcohol }(n=78)\end{array}$ & $\begin{array}{l}\text { HM, silver sulfadiazine, and } \\
\text { ethyl alcohol groups received } \\
\text { topical application of } \\
\text { respective substances by a } \\
\text { sterile gauze or swab on } \\
\text { umbilical stump area } 3 \text { hours } \\
\text { after birth time and continued } \\
\text { every } 8 \text { hours till two days after } \\
\text { UCS; DCC: NI. }\end{array}$ & UCST & $\begin{array}{c}\text { Ahmadpour-Kacho et al., } \\
\text { 2006, Iran [24] }\end{array}$ \\
\hline $\begin{array}{l}\text { Abbaszadeh et al., } \\
\text { 2016, Iran [25] }\end{array}$ & $\begin{array}{c}\text { HM }(n=80) \\
\text { chlorhexidine }(n=82)\end{array}$ & $\begin{array}{l}\text { HM (fresh milk) and } \\
\text { chlorhexidine groups received } \\
\text { topical application of pertinent } \\
\text { material to the cord region } \\
\text { from three hours after birth } \\
\text { and every } 12 \text { hours till } 2 \text { days } \\
\text { after the UCS. }\end{array}$ & UCST & $\begin{array}{c}\text { Abbaszadeh et al., 2016, Iran } \\
\text { [25] }\end{array}$ \\
\hline \multicolumn{5}{|c|}{ Diaper dermatitis (contact dermatitis) } \\
\hline $\begin{array}{l}\text { Seifi et al., 2017, Iran } \\
{[26]}\end{array}$ & $\mathrm{HM}(n=15) ; \mathrm{C}(n=15)$ & $\begin{array}{l}\text { HM: they applied HM } 3 \text { times } \\
\text { a day on the diaper area and } \\
\text { allowed the area to dry before } \\
\text { changing nappies; C: NI. }\end{array}$ & $\begin{array}{l}\text { Diaper dermatitis (DR) } \\
\text { severity/five-point } \\
\text { scale }\end{array}$ & HM: $0 \pm 0 ; \mathrm{C}: 1 \pm 1(P<0.05)$ \\
\hline $\begin{array}{l}\text { Gozen et al., 2014, } \\
\text { Turkey [27] }\end{array}$ & $\begin{array}{l}\text { HM }(n=30) \text {; barrier } \\
\text { cream (zinc oxide } 40 \% \text {; } \\
\text { cod liver oil })(n=33)\end{array}$ & $\begin{array}{l}\text { In both groups of HM and } \\
\text { barrier cream, pertinent } \\
\text { topical applications were } \\
\text { applied to the diaper area } \\
\text { during each diaper change for } \\
\text { maximum } 5 \text { days. Diapers } \\
\text { were changed every three } \\
\text { hours (eight times a day). }\end{array}$ & $\begin{array}{l}\text { Clinical improvement/ } \\
\text { four-point scale }\end{array}$ & $\begin{array}{l}\text { HM: } 60 \% \text {; barrier cream: } 93 \% \\
(P<0.002) . H M: 4 \pm 1 \text {; barrier } \\
\text { cream: } 4 \pm 1 \text { days }(P=0.27)\end{array}$ \\
\hline
\end{tabular}

Atopic dermatitis (eczema)

HM: mothers were recommended to rub the hindmilk twice a day on the affected area; $1 \%$ hydrocortisone ointment: a thin layer of ointment was applied twice a day to all areas

\footnotetext{
of the actively diseased skin.
}

Atopic dermatitis (AD) HM: $1 \pm 3 ; 1 \%$ hydrocortisone severity/SCORAD ointment: $2 \pm 3(P=0.43)$
Kasrae et

$\mathrm{HM}(n=54) ; 1 \%$

ointment $(n=50)$ 
TABle 1: Continued.

\begin{tabular}{|c|c|c|c|c|}
\hline $\begin{array}{l}\text { Author, year, and } \\
\text { location }\end{array}$ & Study groups & Intervention & $\begin{array}{l}\text { Variable measured/ } \\
\text { scale }\end{array}$ & Results \\
\hline $\begin{array}{l}\text { Berents et al., 2015, } \\
\text { Norway [28] }\end{array}$ & $\begin{array}{c}\text { HM }(n=9) \text {; emollient } \\
(n=9)\end{array}$ & $\begin{array}{l}\text { HM: by hand milking, the } \\
\text { mothers were to squeeze out } \\
\text { and throw away the first few } \\
\text { droplets of milk and then } \\
\text { squeeze the next droplets } \\
\text { directly from the nipple to the } \\
\text { eczema spot. HM and } \\
\text { emollient: both groups were } \\
\text { treated with moisturizing } \\
\text { cream and this regimen } \\
\text { continued three times a day for } \\
\text { four weeks. }\end{array}$ & $\begin{array}{c}\text { Severity of atopic } \\
\text { dermatitis/SCORAD }\end{array}$ & $\begin{array}{l}\text { No effect was found on eczema } \\
\text { spots treated with topical } \\
\text { application of fresh HM }\end{array}$ \\
\hline
\end{tabular}

Eye diseases

Verd, 2006, Spain

[29]

HM $(n=45)$; antibiotic eye drops $(n=20)$
Ghaemi et al., 2014, Iran [30]

Pishva et al., 1998, Iran [31]
HM or antibiotic eye drops: the mothers applied HM or antibiotic eye drops by physician prescription prospectively.

Colostrum: they disinfected the nipple first and then used a

$10 \mathrm{cc}$ sterile syringe with a

Colostrum $(n=89)$; topical antibiotic $(n=82) ; \mathrm{C}(n=97)$ sterile bistoury for sucking the colostrum and then applied 2 drops of it in each eye; topical antibiotic: they treated with topical erythromycin ointment (0.5\%); C: NI.

HM: requested to instill one drop of their HM into each eye of the baby prior to each breastfeeding (at least four times a day) for the first ten days; C: NI.
CNLO/duration of treatment
HM: 1; local antibiotic: 5 months $(P<0.001)$

Clinical conjunctivitis/ in colostrum was higher than eye discharge culture for 28 days the topical antibiotic group and lower than the control group $(P=0.03)$

Neonatal conjunctivitis occurrencel prophylactic effects

HM: 9.1\%; C: $25.6 \%$

$(P<0.0001)$

Effects of HM on mother

Mohammadzadeh et al., 2005, Iran [8]

HM $(n=78)$; lanolin $(n=74) ; \mathrm{C}(n=73)$

Admasari et al., 2017, Indonesia [7]
HM: mothers rubbed hind milk on the sore area after each breastfeeding; lanolin: mothers were asked to use lanolin locally on the sore and clean it before infant feeding; C: NI. HM: topical application of fresh mother milk; C: povidone-iodine (10\%). In both groups, pertinent substances were applied to the wound area with a cotton

tissue twice a day.
Healing length by observation and questionnaire on the $3 \mathrm{rd}, 5 \mathrm{th}, 7 \mathrm{th}$, and 10th days

The healing time in the lanolin group was longer than the HM $(P=0.029)$ and the $C$ group

$$
(P=0.028)
$$

Perineal ulcer severity/ REEDA

AE: atopic eczema; C: control; CNLO: congenital nasolacrimal duct obstruction; DCC: dry cord care; GA: gestational age; HM: human milk; NICU: neonatal intensive care unit; NI: no intervention; UCS: umbilical cord separation; UCST: umbilical cord separation time.

study. The UCST was lower ( $4 \pm 1$ days) in THM than the ethanol group $(8 \pm 2$ days $)(P<0.001)[23]$.

In 2006, Vural and Kisa examined the effect of THM compared with povidone-iodine and DCC on UCST among 150 healthy neonates. The UCST was shorter in THM $(7 \pm 2$ days) and DCC ( $8 \pm 3$ days) than that in the povidone-iodine group $(10 \pm 3$ days $)(P<0.05)$ [4]. In the same year, Ahmadpour-Kacho et al. compared the effect of THM with $96 \%$ ethyl alcohol and silver sulfadiazine on UCST among
312 newborns. The findings of this research reported that UCST was significantly different in THM ( $5 \pm 2$ days) than those in the ethyl alcohol (6 \pm 2 days), silver sulfadiazine (10 \pm 4 days), and control groups $(7 \pm 2$ days $)(P<0.001)$ [24]. Furthermore, Abbaszadeh et al. compared UCST between THM and chlorhexidine groups. The UCST was significantly shorter in the THM group ( $7 \pm 2$ days) than that in the chlorhexidine group $(13 \pm 7$ days $)(P<0.001)$ [25]. The bacterial colonization and UCST were compared in the 
THM, 4\% chlorhexidine, and DCC groups in premature neonates. The UCST was reported in the THM, chlorhexidine, and DCC groups as $9 \pm 2,14 \pm 3$, and $11 \pm 3$ days, respectively. The levels of bacterial colonization in THM, chlorhexidine, and DCC groups were $22.9 \%, 71.4 \%$, and $2.9 \%$ in the $5 \pm 1$ days after intervention, respectively $(P<0.001)[16]$.

UCST is a complex process, in which the nucleophilic polymorphocytes penetrate the area between the body and cord, induce digestion of the umbilical cord and ultimately separate these two segments [41, 45-47]. Moisture and bacterial concentration are the most important factors that barricade the UCST process [40]. It is suggested that HM optimizes and accelerates the aforementioned process using its distinguished components including proteins and antibodies $[48,49]$. The antimicrobial proteins can inhibit the pathogenic microorganisms by making the environment unpleasant for the commensal flora, the $\mathrm{pH}$, or bacterial substrates. Additionally, some of these antimicrobial proteins can kill a broad spectrum of bacteria by various mechanisms [50]. Of these proteins, the leukocytes found in $\mathrm{HM}$, along with other immunologic factors, play a crucial role in the removal of the umbilical cord [35].

The secreted HM in the first days after the childbirth is called colostrum. The colostrum contains substantial amounts of the aforementioned components compared with the mature HM, which may explain the effectiveness of this component when compared with mature HM [22].

4.1.2. Diaper Dermatitis (Contact Dermatitis). Diaper dermatitis (DR) is a common source of inflammation in neonates [51], and its prevalence has been reported to be up to $50 \%$ [52]. DR in the long term can damage the skin seriously leading to secondary infections and skin ulcers [53]. The long-term exposure with urine and feces may break down the skin integrity due to the presence of lipase and protease enzymes in urine [54]. Moreover, the analysis of urea by bacteria existing in the stool may cause increased ammonia and subsequently enhanced skin $\mathrm{pH}$, which in turn makes the skin more susceptible to infection in infants who wear the diaper [55]. Several studies assessed the effect of HM on DR treatment.

Seifi et al. conducted an RCT to assess the impact of THM on DR with recruiting 30 neonates aged 0-12 months. The daily application of THM on the skin indicated a significant difference between the THM and the control group on the third day $(P=0.004)[26]$. On the other hand, Gozen et al. compared the THM and a barrier cream among 63 neonates in an RCT design. Although no significant difference was found between two groups in terms of recovery length of DD $(P=0.294)$, a significantly higher wound healing was found in the THM than the barrier cream group $(P=0.002)$ [27].

The finding from relevant studies suggested that the presence of a variety of vitamins and minerals in HM makes the skin soft and smooth and prevents dryness and fragility, thereby preventing the penetration of foreign microorganisms through the skin [56]. HM accomplishes this function by its natural lactic acid that artificially existed in many skin creams and lotions. Additionally, fatty acids of HM have hydrophobic properties preventing the skin penetration and damages caused by urea and enzymes in the stool and urine [9].

4.1.3. Atopic Dermatitis (Eczema). Literature has shown that breastfeeding, especially in the first weeks of postpartum, has a significant influence on reducing allergic disorders including atopic dermatitis (AD) [4]. Some studies have shown that the application of HM topically can also heal the AD.

Kasrae et al. showed that THM can be effective in shortening the AD duration as much as hydrocortisone (1\%) in children [13]. However, the findings from the study conducted by Berents et al. comparing the THM and control groups did not show a significant difference between the two groups [28].

HM consists of many natural immunologic and antiinfective agents that have strong antimicrobial functions, which offer specific and nonspecific passive immunities [57]. Apart from that, the fatty acids including $n-3$ long-chain polyunsaturated fatty acids (LCPs) and ruminant fatty acids have an important role in the curative effect of HM [58]. Also, a group of inflammatory cytokines such as IL-I $\beta$ as well as CD14 protein are shown to be associated with eczema [59].

4.1.4. Eye Disease. The use of HM in the treatment of eye diseases was investigated in a study by Gagnon who lived in a marginalized area of Malawi. Due to the lack of access to the required treatment facilities, the researcher tended to use traditional methods, such as THM in the treatment of optic inflammation [60]. Also, a retrospective study assessed the effect of THM on the treatment of congenital nasolacrimal duct obstruction (CNLO) in children. The evidence revealed that the treatment with local antibiotics took a significantly higher time (5 days) than that in the THM group (1 day) $(P<0.001)$ [29]. Furthermore, Ghaemi et al. examined the prophylactic effect of colostrum on neonatal conjunctivitis. In this study, a total of 268 neonates were allocated into three groups: colostrum $(n=89)$, control (no intervention) $(n=97)$, and topical erythromycin $(0.5 \%)(n=82)$ groups. According to results, the frequency of conjunctivitis was higher in the control group, in comparison with those receiving topical colostrum and topical erythromycin $(0.5 \%)$ $(P=0.03)$ [30]. A similar study in 1998 on 565 newborns had demonstrated that conjunctivitis occurred in $9.1 \%$ and $25.6 \%$ of the children in the HM and control (no intervention) groups, respectively, showing a significant difference between two groups $(P<0.00001)$ [31].

The explored promising effects of HM and especially colostrum on optical diseases may be due to the presence of a great number of antibacterial agents [38]. The lipids in HM seem to mediate the association between THM and conjunctivitis by protecting the body against invasive infections [35].

4.2. Effects of HM on Mothers. Multiple studies are concerned with THM effects on a variety of skin damages and infections in mothers. These include the following: 
Nipple Sore. Nipple irritation is one of the most common complications in breastfeeding women. It was reported that $96 \%$ of mothers tend to not lactate due to nipple pain and ulcer during breastfeeding [61]. Since nipple-related damages and subsequent pains are important factors in the mother's decision to stop lactation, choosing the appropriate intervention is a dire need. Mohammadzadeh et al. assessed the effect of HM and lanolin on the sore nipple. The data from the study demonstrated a longer recovery time in the lanolin group when compared to those in the THM group $(P=0.029)$ [8].

Perineal Ulcer. Approximately $85 \%$ of women undergo the episiotomy (perineal area cut) during labor, of which $69 \%$ need suture in the area [62]. Due to the high moisture and low ventilation, the perineal area seems to be a proper environment for the growth of bacteria and invasive microorganisms $[7,63]$. The perineal inflammations lead to the mother's pain and discomfort and consequently reduced the ability to take care of herself, the baby, and the family. Studies also have indicated the septic shock and death in long-term infection of the perineum [64].

Admasari et al. suggested THM as an alternative method to the perineal ulcer. Their study aimed to compare the healing of the perineal ulcer in the povidone-iodine (10\%) and THM groups. The results showed that the THM group (11 days) had a significantly shorter wound healing process than the povidone-iodine (10\%) (20 days) groups $(P=0.002)$ [7]. The stem cells in the HM, along with other anti-inflammatory and antioxidant components, may explain the effectiveness and noninvasive protective properties of HM against various types of ulcers [65].

The usage of HM for numerous types of wounds has been known for several decades in some countries [17]. Some of the beneficial effects of HM in response to life-threatening inflammations on mother and infant may be related to the biologically active factors including growth factors such as epidermal growth factor (EGF) and insulin-like growth factor (IGF) superfamily and CD14 protein as well as adipokines and inflammatory cytokines [59].

Growth factors are necessary elements to activate the process of granulation (inflammatory phase) and epithelization (proliferative phase), as required phases for wound healing [66]. IGF-1 as a unique independent growth factor attributes an anabolic feature which helps alleviate skin or mucosal injuries and also diminish the catabolism process [4].

Also, a group of bioactive and anti-inflammatory molecules were known as proresolving mediators (SPMs) that can eliminate the infectious microorganisms, inflammation, and pain in the wound area. Even though the exact mechanism of action remains uncertain, it seems that HM may be a safe and natural substance against foreign and invasive microorganisms due to its rich source of growth factor, anti-inflammatory agents, antibacterial agents, and immunity factors [7].

4.3. Limitations and Future Research. The reviewed research articles displayed the positive effect of THM on various damages such as dermal and mucosal injuries. However, more research with a homogenous methodology is needed to confirm the potential advantages and disadvantages of THM on the discussed injuries. Additionally, the examination of THM on the different damages and pathogenesis may be beneficial to reach certainty in terms of curative properties of THM. In this review paper, we only gathered recent and basic articles to help shed light on the topical effects of HM. Therefore, other articles on this topic may exist that were outside of our specified date range.

\section{Conclusion}

According to the results of the current set of studies reviewed, there is a general agreement on the positive effects of the THM on the prevention and treatment of common maternal and infantile complications including lesions and sores with/without secondary infections. To date, no adverse side effects following the THM application have been reported. HM may be an accessible, safe, and appropriate alternative for the treatment of damages of skin and mucus tissues with various origins in mothers and infants.

$\begin{array}{ll}\text { Abbreviations } \\ \text { WHO: } & \text { World Health Organization } \\ \text { CINAHL: } & \text { Cumulative Index to Nursing and Allied } \\ & \text { Health Literature } \\ \text { GBS: } & \text { Group B Streptococcus } \\ \text { UCST: } & \text { Umbilical cord separation time } \\ \text { AE: } & \text { Atopic eczema } \\ \text { SCORAD: } & \text { SCORing Atopic Dermatitis } \\ \text { LCPs: } & \text { Long-chain polyunsaturated fatty acids } \\ \text { TGF-A and } & \text { Transforming growth factors of alpha and } \\ \text { TGF-B: } & \text { beta } \\ \text { IGF-1 and } & \text { Insulin-like growth factors 1 and } 2 \\ \text { IGF-2: } & \\ \text { HM: } & \text { Human milk } \\ \text { THM: } & \text { Topical human milk } \\ \text { DCC: } & \text { Dry cord care } \\ \text { NICU: } & \text { Neonatal intensive care unit } \\ \text { UCS: } & \text { Umbilical cord separation } \\ \text { NI: } & \text { No intervention } \\ \text { GA: } & \text { Gestational age } \\ \text { AE: } & \text { Atopic eczema } \\ \text { C: } & \text { Control } \\ \text { CNLO: } & \text { Congenital nasolacrimal duct obstruction. }\end{array}$

\section{Conflicts of Interest}

The authors declare that they have no conflicts of interest.

\section{Authors' Contributions}

Zahra Sharifi-Heris and Leila Amiri-Farahani designed the study and analyzed and interpreted the data. Moreover, Zahra Sharifi-Heris, Leila Amiri-Farahani, and Faraz Mojab wrote and revised the paper. 


\section{Acknowledgments}

The authors thank the professors of the Midwifery Department, Iran University of Medical Sciences, Tehran, Iran.

\section{References}

[1] C. G. Victora, R. Bahl, A. J. D. Barros et al., "Breastfeeding in the 21st century: epidemiology, mechanisms, and lifelong effect," The Lancet, vol. 387, no. 10017, pp. 475-490, 2016.

[2] B. L. Murch, B. A. de Sousa, and C. L. de Mola, "Breastfeeding and neurodevelopmental outcomes," Current Opinion in Clinical Nutrition \& Metabolic Care, vol. 21, no. 3, pp. 174178, 2018.

[3] J. T. Baynham, M. A. Moorman, C. Donnellan, V. Cevallos, and J. D. Keenan, "Antibacterial effect of human milk for common causes of paediatric conjunctivitis," British Journal of Ophthalmology, vol. 97, no. 3, pp. 377-379, 2013.

[4] G. Vural and S. Kisa, "Umbilical cord care: a pilot study comparing topical human milk, povidone-iodine, and dry care," Journal of Obstetric, Gynecologic \& Neonatal Nursing, vol. 35, no. 1, pp. 123-128, 2006.

[5] Australian Breastfeeding Association, "Topical treatment with breastmilk: randomised trials," 2015, https://www.breastfeeding. asn.au/tropical-treatment-with-breastmilk-randomised-trials.

[6] J. M. Herlihy, A. Shaikh, A. Mazimba et al., "Local perceptions, cultural beliefs and practices that shape umbilical cord care: a qualitative study in Southern Province. Zambia," PLoS One, vol. 8, no. 11, Article ID e79191, 2013.

[7] Y. Admasari, B. Santoso, T. Suherni, I. D. Mashoedi, and M. Mardiyono, "Breast milk as an alternative for postpartum perineal care," Belitung Nursing Journal, vol. 3, no. 3, pp. 238-245, 2017.

[8] A. Mohammadzadeh, A. Farhat, and H. Esmaeily, "The effect of breast milk and lanolin on sore nipples," Saudi Medical Journal, vol. 26, no. 8, pp. 1231-1234, 2005.

[9] N. J. Andreas, B. Kampmann, and K. Mehring Le-Doare, "Human breast milk: a review on its composition and bioactivity," Early Human Development, vol. 91, no. 11, pp. 629-635, 2015.

[10] S. Damarini, E. Eliana, and M. Mariati, "Efektivitas sirih merah dalam perawatan luka perineum di Bidan praktik mandiri," Kesmas: National Public Health Journal, vol. 8, no. 1, pp. 39-44, 2013.

[11] Z. Sharifi-Heris, L. A. Farahani, H. Haghani, S. AbdoliOskouee, and S. B. Hasanpoor-Azghady, "Comparison the effects of topical application of olive and calendula ointments on Children's diaper dermatitis: a triple-blind randomized clinical trial," Dermatologic Therapy, vol. 31, no. 6, Article ID e12731, 2018.

[12] G. A. Mahmoudi, V. Almasi, N. Lorzadeh, and A. Khansari, "The reasons for using and not using alternative medicine in Khorramabad women, west of Iran," JPMA. The Journal of the Pakistan Medical Association, vol. 65, no. 6, pp. 623-625, 2015.

[13] H. Kasrae, L. Amiri Farahani, and P. Yousefi, "Efficacy of topical application of human breast milk on atopic eczema healing among infants: a randomized clinical trial," International Journal of Dermatology, vol. 54, no. 8, pp. 966-971, 2015.

[14] R. Whittemore and K. Knafl, "The integrative review: updated methodology," Journal of Advanced Nursing, vol. 52, no. 5, pp. 546-553, 2005.
[15] A. Liberati, D. G. Altman, J. Tetzlaff et al., "The PRISMA statement for reporting systematic reviews and meta-analyses of studies that evaluate health care interventions: explanation and elaboration," PLoS Medicine, vol. 6, no. 7, Article ID e1000100, 2009.

[16] D. Lyngdoh, S. Kaur, P. Kumar, V. Gautam, and S. Ghai, "Effect of topical application of human breast milk versus $4 \%$ chlorhexidine versus dry cord care on bacterial colonization and clinical outcomes of umbilical cord in preterm newborns," Journal of Clinical Neonatology, vol. 7, no. 1, p. 25, 2018.

[17] N. A. Allam, A. Wafa, and A. M. Talat, "The effect of topical application of mother milk on separation of umbilical cord for newborn babies," American Journal of Nursing Science, vol. 4, no. 5, pp. 288-296, 2015.

[18] A. Aghamohammadi, M. Zafari, and L. Moslemi, "Comparing the effect of topical application of human milk and dry cord care on umbilical cord separation time in healthy newborn infants," Iranian Journal of Pediatrics, vol. 22, no. 2, pp. 158-62, 2012.

[19] S. Pujar, M. Deepa, and F. Francis, "Breast milk application-an emerging trend to reduce timing of cord separation (tcs) among newborns," IOSR Journal of Nursing and Health Science, vol. 1, no. 4, pp. 39-42, 2013.

[20] A. R. Dhanawade, "A study to assess the effectiveness of breast milk application on umbilical cord stump among newborns of mother's undergone caesarean section in tertiary care maternity hospitals of Sangli, miraj, kupwad corporation area," Innovations in Pharmaceuticals and Pharmacotherapy, vol. 2, no. 3, pp. 386-394, 2014.

[21] L. Amiri-Farahani, M. Taffazoli, and A. Mohammadzadeh, "Effect of topical application of breast milk and dry cord care on umbilical cord separation time in neonates," Journal of Sabzevar University of Medical Sciences, vol. 14, no. 3, pp. 165-171, 2007.

[22] M. Golshan and N. Hossein, "Impact of ethanol, dry care and human milk on the time for umbilical cord separation," Journal of Pakistan Medical Association, vol. 63, no. 9, pp. 1117-1119, 2013.

[23] E. S. Mahrous, M. M. Darwish, S. A. Dabash, I. Marie, and S. F. Abdelwahab, "Topical application of human milk reduces umbilical cord separation time and bacterial colonization compared to ethanol in newborns," Translational Biomedicine, vol. 3, no. 1, pp. 1-10, 2012.

[24] M. Ahmadpour-Kacho, Y. Zahedpasha, K. Hajian, G. Javadi, and H. Talebian, "The effect of topical application of human milk, ethyl alcohol 96\%, and silver sulfadiazine on umbilical cord separation time in newborn infants," Archives of Iranian Medicine, vol. 9, no. 1, pp. 33-38, 2006.

[25] F. Abbaszadeh, Z. Hajizadeh, and M. Jahangiri, "Comparing the impact of topical application of human milk and chlorhexidine on cord separation time in newborns," Pakistan Journal of Medical Sciences, vol. 32, no. 1, p. 239, 2016.

[26] B. Seifi, S. Jalali, and M. Heidari, "Assessment effect of breast milk on diaper dermatitis," Dermatology Reports, vol. 9, no. 1, p. 7044, 2017.

[27] D. Gozen, S. Caglar, S. Bayraktar, and F. Atici, "Diaper dermatitis care of newborns human breast milk or barrier cream," Journal of Clinical Nursing, vol. 23, no. 3-4, pp. 515-523, 2014.

[28] T. L. Berents, J. Rønnevig, E. Søyland, P. Gaustad, G. Nylander, and B. F. Løland, "Topical treatment with fresh human milk versus emollient on atopic eczema spots in young children: a small, randomized, split body, controlled, blinded pilot study," BMC Dermatology, vol. 15, no. 1, p. 7, 2015. 
[29] S. Verd, "Switch from antibiotic eye drops to instillation of mother's milk drops as a treatment of infant epiphora," Journal of Tropical Pediatrics, vol. 53, no. 1, pp. 68-69, 2006.

[30] S. Ghaemi, P. Navaei, S. Rahimirad, M. Behjati, and R. Kelishadi, "Evaluation of preventive effects of colostrum against neonatal conjunctivitis: a randomized clinical trial," Journal of Education and Health Promotion, vol. 3, p. 63, 2014.

[31] N. Pishva, M. Mehryar, H. Mahmoudi, and R. Farzan, "Application of topical breast milk for prevention of neonatal conjunctivitis," Iranian Journal of Medical Science, vol. 23, p. 55, 1998.

[32] I. Ten-Doménech, E. Beltrán-Iturat, J. M. Herrero-Martínez, J. V. Sancho-Llopis, and E. F. Simó-Alfonso, “Triacylglycerol analysis in human milk and other mammalian species: smallscale sample preparation, characterization, and statistical classification using HPLC-ELSD profiles," Journal of Agricultural and Food Chemistry, vol. 63, no. 24, pp. 5761-5770, 2015.

[33] H. Demmelmair and B. Koletzko, "Variation of metabolite and hormone contents in human milk," Clinics in Perinatology, vol. 44, no. 1, pp. 151-164, 2017.

[34] B. Koletzko, "Human milk lipids," Annals of Nutrition and Metabolism, vol. 69, no. Suppl. 2, pp. 27-40, 2016.

[35] F. Mosca and M. L. Giannì, "Human milk: composition and health benefits," La Pediatria Medica e Chirurgica, vol. 39, no. 2, pp. 47-52, 2017.

[36] B. Lönnerdal, "Bioactive proteins in breast milk," Journal of Paediatrics and Child Health, vol. 49, pp. 1-7, 2013.

[37] A. M. Zivkovic, J. B. German, C. B. Lebrilla, and D. A. Mills, "Human milk glycobiome and its impact on the infant gastrointestinal microbiota," Proceedings of the National Academy of Sciences, vol. 108, no. Supplement_1, pp. 4653-4658, 2011.

[38] W. L. Hurley and P. K. Theil, "Perspectives on immunoglobulins in colostrum and milk," Nutrients, vol. 3, no. 4, pp. 442-474, 2011.

[39] K. Le Doare and B. Kampmann, "Breast milk and Group B streptococcal infection: vector of transmission or vehicle for protection?" Vaccine, vol. 32, no. 26, pp. 3128-3132, 2014.

[40] D. Stewart and W. Benitz, "Umbilical cord care in the newborn infant," Pediatrics, vol. 138, no. 3, Article ID e20162149, 2016.

[41] World Health Organization, WHO Recommendations on Newborn Health: Guidelines Approved by the WHO Guidelines Review Committee (No. WHO/MCA/17.07), World Health Organization, Geneva, Switzerland, 2017.

[42] M. Taffazoli, L. A. Farahani, A. Mohammadzadeh, H. Esmaeeli, and K. Ghazvini, "Dose topical application of breast milk affect on bacterial colonization in umbilical cord?" Koomesh, vol. 10, no. 1, pp. Pe29-Pe35, 2008.

[43] S. Ibhanesebhor and E. S. Otobo, "In vitro activity of human milk against the causative organisms of ophthalmia neonatorum in Benin City, Nigeria," Journal of Tropical Pediatrics, vol. 42, no. 6, pp. 327-329, 1996.

[44] K. H. Ramsey, C. E. Poulsen, and P. P. Motiu, "The in vitro antimicrobial capacity of human colostrum against Chlamydia trachomatis," Journal of Reproductive Immunology, vol. 38, no. 2, pp. 155-167, 1998.

[45] T. P. McConnell, C. W. Lee, M. Couillard, and W. W. Sherrill, "Trends in umbilical cord care: scientific evidence for practice," Newborn and Infant Nursing Reviews, vol. 4, no. 4, pp. 211-222, 2004.

[46] A. K. Suliman, H. Watts, J. Beiler et al., "Triple dye plus rubbing alcohol versus triple dye alone for umbilical cord care," Clinical Pediatrics, vol. 49, no. 1, pp. 45-48, 2010.
[47] J. Zupan, P. Garner, and A. A. Omari, "Topical umbilical cord care at birth," Cochrane Database of Systematic Reviews, vol. 3, no. 3, Article ID CD001057, 2004.

[48] N. A. El-Hamid and H. F. Azzam, "Effect of two different cord care regimens on umbilical cord stump separation time among neonates at Cairo university hospitals, department of maternal and newborn health nursing," Journal of American Science, vol. 7, no. 12, pp. 920-926, 2011.

[49] K. Park, Textbook of Preventive and Social Medicine: M/S Banarsidas Bhanot, J. P Lippincott, Oliver Wyman, 2006.

[50] M. S. Kramer, B. Chalmers, E. D. Hodnett et al., "Promotion of breastfeeding intervention trial (PROBIT)," Jama, vol. 285, no. 4 , p. $413,2001$.

[51] P. Collet, J. S. Wallace, and N. C. Pace, "Diaper dermatitis: a review and update," Current Opinion in Pediatrics, vol. 24, no. 4, pp. 472-479, 2012.

[52] A. Kimberly and M. Horii, "Diaper rash in infants and children," 2017, https://www.uptodate.com/contents/diaperrash-in-infants-and-children-beyond-the-basics.

[53] Z. Afshari, M. Jabraeili, M. Asaddollahi, M. Ghojazadeh, and Y. Javadzadeh, "Comparison of the effects of chamomile and calendula ointments on diaper rash," Evidence Based Care Journal, vol. 5, no. 2, pp. 49-56, 2015.

[54] J. Rowe, E. McCall, and B. Kent, "Clinical effectiveness of barrier preparations in the prevention and treatment of nappy dermatitis in infants and preschool children of nappy age," International Journal of Evidence-Based Healthcare, vol. 6, no. 1, pp. 3-23, 2008.

[55] L. M. Heimall, B. Storey, J. J. Stellar, and K. F. Davis, "Beginning at the bottom," MCN, The American Journal of Maternal/Child Nursing, vol. 37, no. 1, pp. 10-16, 2012.

[56] S. viðStreym, C. S. Højskov, U. K. Møller et al., "Vitamin D content in human breast milk: a 9-mo follow-up study," The American Journal of Clinical Nutrition, vol. 103, no. 1, pp. 107114, 2015.

[57] P. Brandtzaeg, "Mucosal immunity: integration between mother and the breast-fed infant," Vaccine, vol. 21, no. 24, pp. 3382-3388, 2003.

[58] C. Thijs, A. Müller, L. Rist et al., "Fatty acids in breast milk and development of atopic eczema and allergic sensitisation in infancy," Allergy, vol. 66, no. 1, pp. 58-67, 2011.

[59] A. Van Ree, S. M. Arribas, A. Algara et al., "A review of bioactive factors in human breastmilk: a focus on prematurity," Nutrients, vol. 11, no. 6, p. 1307, 2019.

[60] L. Gagnon, "Investigating traditional eye medicines in Malawi," International Development Research Center, vol. 14, pp. $1-3,2000$.

[61] A. Y. Loke and L. K. S. Chan, "Maternal breastfeeding selfefficacy and the breastfeeding behaviors of newborns in the practice of exclusive breastfeeding," Journal of Obstetric, Gynecologic \& Neonatal Nursing, vol. 42, no. 6, pp. 672-684, 2013.

[62] R. McCandlish, U. Bowler, H. Asten et al., "A randomised controlled trial of care of the perineum during second stage of normal labour," BJOG: An International Journal of Obstetrics and Gynaecology, vol. 105, no. 12, pp. 1262-1272, 1998.

[63] B. J. Garcia, "Selection of incisions for gynecologic procedures," Surgical Clinics of North America, vol. 71, no. 5, pp. 1041-1052, 1991.

[64] A. Johnson, R. Thakar, and A. H. Sultan, "Obstetric perineal wound infection: is there underreporting?" British Journal of Nursing, vol. 21, no. Sup3, pp. S28-S35, 2012.

[65] F. Kakulas, "Breast milk: a source of stem cells and protective cells for the infant," Stem Cells, vol. 11, no. 6, p. 3, 2015.

[66] B. R. Thapa, "Health factors in colostrum," The Indian Journal of Pediatrics, vol. 72, no. 7, pp. 579-581, 2005. 